visit a cross-section of industry, some three hundred or three hundred and fifty firms, and to investigate how scientific information reaches a firm, the obstacles, and the methods by which the obstacles might be overcome. The inquiry might reveal the need for a regional institute of the type of the Mellon Institute; but an attempt would also be made to assess the means whereby scientific methods and technical knowledge could immediately be applied to increase productivity. New staff would be required for the survey, and in this it was hoped that industrial estahlishments would assist.

\section{Activities of Political and Economic Planning}

A BROADSHEET, "Peview of a Programme", issued by Political Economic Planning (No. 289, October 38 (948) $^{9}$ is of general interest as, besides reyienfing the progress of work outlined in a siknilar broadsheet in 1946, it describes the new work on which P E P is now engaged. Some of his work, notably the inquiry into the future of British universities and that into the relations between Government and industry in the new context of central economic planning, is of special interest here. The first of these will draw on and develop the discussion of university training in the report on man-power policy now completed, as well as the examination of the administrative framework of the education system in the broadsheet on "Councils and their Schools". The group conducting the inquiry consists mainly of university 'dons' with a number of laymen and of corresponding members. The second inquiry, which is not yet properly under way, will examine first the assumptions that must be made about the nature of the instructions which the Government gives to industry and the conditions which make it necessary for the State to issue them. Next, the inquiry will examine in broad terms those measures of Government which affect the working of industry, before proceeding to consider the common purpose which business shares with industry, the nature of the general decisions which Government has to take, the division of responsibility between Government and industry for the execution of policy and the methods and machinery by which policy is drawn up in effective collaboration with industry. The central problem of the inquiry will be to discover how programmes can be met without the Government having to decide in detail what people are to make and where they are to work.

As regards the work already carried out, the broadsheet gives a concise review of the progress made and indicates the broadsheets or reports already published and the position of others which are in the final stages. These include a report on the engineering industries and the various broadsheets from the "Active Democracy" Group. A third major inquiry, into housing policy, is being conducted by a group formed in July 1948 to report in 1950 on the principal elements of a long-term housing policy, and particularly to define the issues, the possible alternatives and the implications involved in each. in 6 German Jute Industry during 1939-45

IN B.I.O.S. Werall Report No. 17 (London : H.M.

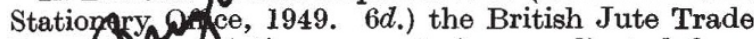
Rpeafch Ass liation presents in co-ordinated form dat en the jute industry in Germany during the period 1939-45, which has been given in two earlier moin reports from the British Intelligence Objectives Sub-Committee and in other intelligence surveys.
Alternative raw materials used in this industry during the period were mainly paper; but regenerated cellulose and naturally occurring cellulosic fibres of European origin, such as green flax and green hemp, were also used. The report includes notes on the emulsifying agents, such as 'Emulphors', used in batching jute, on sizing agents in use, as well as products such as 'Preventols' used for protecting starches and jute against mildew attack. The most important treatment used for rot-proofing appears to be the cuprammonium process, and some work has also been carried out on flame-proofing and waterproofing. For impermeable finishes plasticized polyvinyl chloride, 'Igelit', was largely used, as well as emulsion coatings of polyvinyl acetate, 'Mowilith'. For water-repellent finishes hydrophobic metallic soaps were used extensively, including the proprietary emulsions of waxes and aluminium salts known as 'Ramasits'. No information was collected on the methods employed in bleaching or dyeing jute; but the report includes notes on methods in use for testing paper and textiles, particularly single-fibre testing and mechanical devices for estimating the evenness of yarns.

\section{The Textile Institute}

Co-operation between textile technologists in Great Britain ond the United States has been strength. ened by the formation of a panel of American technolggists in New York, which consists of eight leadins American men of science, of whom Mr. R. J. Kepr-Muir, president of Lustre Fibres, Inc., is the hairman. The panel is intended to provide general liaison between the Textile Institute, which is the official international organisation of textile tech. nologists, and technologists in the United States and it is hoped that by an exchange of British and American ideas on textile education, reciprocal visits of teaching staff, a wider distribution in the United States of the Journal of the Textile Institute and by collaboration with publishers of similar scientific journals in America, a general advancement of technological knowledge will result throughout the whole industry. There are at present some 130 members of the Textile Institute in the United States, including more than twenty fellows and five associates. Two hundred organisations also subscribe to the Journal.

A new Section of the Textile Institute has been formed to serve the South Wales and Monmouthshire area, which has recently been entered by various branches of the textile industry. An inaugural meeting will be held at the South Wales Institute of Engineers, Park Place, Cardiff, on April 4 at 7.30 p.m., when the president of the Institute, Mr. J. Foster Beaver, will speak on "The Textile Institute, Its Aims and Objectives". The new Section brings the total number of sections of the Textile Institute to fourteen. Radio Communication anderie Upper Atmosphere THe Department of Scientific and Industrial Appleton and Or. W. J. G. Beynon entitled "Radio Researd Special Report No. 18: The Application af Dondspheric Data to Radio Communication" (London: H.M. Stationery Office, 1948; 1s. net). This publication comprises a reprint in a single booklet of two papers published by the authors in the Proceedings of the Physical Society in 1940 and 1947 together with material taken from confidential reports circulated during the War and now published for the first time. A large portion of the report is of 